\title{
25 Research Square \\ Innate and Adaptive Immune Responses Induced by A. Fumigatus Conidia and Hyphae
}

\section{Yingzhi Luo}

Nanjing University

\section{Fang Liu}

Nanjing Jinling Hospital: East Region Military Command General Hospital

Jie Xu

Nanjing Jinling Hospital: East Region Military Command General Hospital

Qingtao Kong

Nanjing Jinling Hospital: East Region Military Command General Hospital

Yi Shi

Nanjing Jinling Hospital: East Region Military Command General Hospital

Hong Sang ( $\nabla$ sanghong@nju.edu.cn )

Nanjing Jinling Hospital: East Region Military Command General Hospital https://orcid.org/00000001-7188-6740

\section{Research Article}

Keywords: Aspergillus fumigatus, conidia, hyphae, immune response, Th1/Th2/Th17

Posted Date: May 27th, 2021

DOl: https://doi.org/10.21203/rs.3.rs-528718/v1

License: (c) (i) This work is licensed under a Creative Commons Attribution 4.0 International License.

Read Full License 


\section{Abstract}

Purpose Previous research indicated hyphae of $A$. fumigatus rather than conidia could successfully build pulmonary aspergillosis model in immunocompetent mice. In this study, we compared the immune responses induced by hyphae and conidia, making a preliminary explanation for the phenomenon.

Methods Macrophages and PBMCs were respectively stimulated by $A$. fumigatus hyphae and conidia and immunological changes were measured in vitro. Male C57BL/6 mice were challenged with conidia and hyphae through intratracheal inoculation. Dynamic conditions of mice were recorded and their immune responses were measured by RNA-seq.

Results The results confirmed that hyphae could induce more intensive inflammation than conidia. However, macrophages revealed a higher production of ROS as well as M1 polarization in response to conidia stimuli. In addition, conidia could promote Th1 cell differentiation, while hyphae could increase the $\mathrm{CD} 4 / \mathrm{CD} 8$ ratio.

RNA-seq validated that multiple immunologically relevant pathways were much more strongly activated by hyphae, which also promoted Th2 cell differentiation and suppressed Th1 cell differentiation. Both hyphae and conidia could activate Th17 cell differentiation.

Conclusion Conidia and hyphae induced different immune responses and the immune responses against conidia played a better protective role.

\section{Introductions}

Pulmonary aspergillosis refers to a spectrum of clinical syndromes caused by airborne aspergillus spp.a series of saprophytic moulds abundant in indoor and outdoor environments that mainly affected the respiratory tract of immunocompromised patients. Depending on the host characteristics, aspergillosis was categorized into invasive pulmonary aspergillosis (IPA), chronic pulmonary aspergillosis (CPA) and allergic bronchopulmonary aspergillosis (ABPA) [1-4]. With the widespread use of broad-spectrum antibiotics and immunosuppressive agents, the high incidence of aspergillosis remains to be a public concern[5-8]. Moreover, the ongoing pandemic of coronavirus disease 2019 (COVID-19) has shown a high frequency of co-infection with aspergillus spp., leading to terrible clinical results and a heavy medical burden[9-14].

Aspergillus fumigatus (A. fumigatus) is the most common etiologic species of aspergillosis. In its life cycle, numerous asexual conidia are produced and spread, which can be inhaled by humans and easily reach the alveoli owing to their tiny size[15]. For immunocompetent individuals, invading conidia will get cleared by airway immune systems including epithelium and its secretions, macrophages, neutrophils and other immune cells. Once the host immune system gets compromised, the conidia unable to eliminate will swell and germinate to form invasive hyphae, resulting in different types of aspergillosis[15, 16]\{van de Veerdonk, 2017 \#90\}. The mechanism of host immunity against aspergillus is stage-specific. 
During swelling and germination, the outermost hydrophobic rodlet layer of conidia gets lost and the melanin layer is disorganized, thus exposing the inner layer $\beta-1,3-g l u c a n[17]$. These molecular changes account for various pathogen-associated molecular patterns (PAMPs) in the surface of $A$. fumigatus conidia and hyphae. As for host immune system, various pathways are activated to defend against the pathogen via specific pattern recognition receptors (PRRs), such as toll-like receptors (TLRs) and C-type lectin receptors (Clecs). They can recognize the particular PAMPs in the surface of conidia or hyphae and trigger a series of pro-inflammatory and anti-inflammatory reactions[16].

In the past decades, researchers focused much more on conidia as the inhalable causative agents of pulmonary aspergillosis. However, hyphal fragments can also be airborne and directly invade the respiratory tract $[18,19]$. It's not uncommon to see that nonsporulating moulds especially $A$. fumigatus to be isolated and identified as the pathogenic microorganism in the respiratory tract samples[20]. We had previously obtained two clinical nonsporulating $A$. fumigatus strains from the pulmonary specimens of two immunocompetent patients. To prove their pathogenicity, Zhang Z et al found an interesting phenomenon that hyphae of $A$. fumigatus rather than conidia could cause pulmonary aspergillosis in immunocompetent hosts[21]. It was also reported that hyphal fragments could induce more potent inflammation than conidia, indicating hyphae may have stronger immunogenicity[22].

The main objective of this study was to compare host immune responses against airborne conidia and hyphae. Immune cells were exposed to live and heat-inactivated fungi, respectively, to mimic the fungal invasion in vitro. In vivo, the pulmonary infection model in immunocompetent mice was rebuilt by intratracheal injection of conidia or hyphal fragments, respectively, for further exploration of their immunological differences and underlying mechanism.

\section{Materials And Methods}

\section{Mould preparation}

A. fumigatus wild-type strain Af293 (purchased from FGSC, the Fungal Genetics Stock Center, University of Missouri, USA) was cultured in rich media YAG containing $0.5 \%(\mathrm{w} / \mathrm{v})$ yeast extract, $2 \%(\mathrm{w} / \mathrm{v})$ glucose and $0.1 \%(\mathrm{v} / \mathrm{v})$ trace elements at $37^{\circ} \mathrm{C}$. Conidia and hyphal fragments were cultured and harvested as described in a previous study[23]. To compare conidia and hyphal fragments, their surface areas were measured by software Image $\mathrm{J}$ after taking fluorescent pictures with Calcofluor white (Sigma, USA) staining and hemocytometer was used to keep equal volume of each picture. The final concentration of fungal suspension was calculated and standardized by multiplicity of infection (MOI) -ratio of conidia to cells. Conidia and hyphae were inactivated in $95^{\circ} \mathrm{C}$ water bath for 30 minutes.

\section{RAW264.7 macrophages culture and stimulation}

RAW264.7 macrophages were maintained in humidified air at $37^{\circ} \mathrm{C}, 5 \% \mathrm{CO}_{2}$ in DMEM supplemented with $10 \%$ fetal bovine serum (FBS; Gibco, USA). At first, macrophages were either incubated with live conidia (LC), live hyphal fragments (LH), heat-inactivated conidia (HIC) and heat-inactivated hyphal fragments 
$(\mathrm{HIH})$ for different times in order to figure out when inducible nitric oxide synthase (iNOS) mRNA expression changed most significantly (MOI=10). The live aspergillus stimulation should last for no more than 6 hours because of conidia germination. Then macrophages were incubated with gradient concentration of LC and LH for 6 hours, with HIC and HIH for 24 hours (MOI ranging from 0.1 to 100). Supernatants were collected and stored at $-80^{\circ} \mathrm{C}$ until examination.

\section{CCK-8 assay}

Cell Counting Kit-8 (CCK-8) assay was involved to measure the cell viability. RAW264.7 macrophages were plated in 96-well flat bottom culture plates, at a density of $5 \times 10^{3}$ cells/well and incubated overnight. Thereafter, cells were stimulated with gradient live organisms for 6 hours and inactivated ones for 24 hours. After washing with PBS (Hyclone, USA) twice, it was added with fresh medium and $10 \mu \mathrm{L}$ CCK-8 reagent in each well for 1 hour's incubation. Finally, the absorbance value was measured at the wavelength of $450 \mathrm{~nm}$ using an ELISA plate reader. The viability index of the cells was determined, using the following equation:

Cell viability $=\left(A_{\text {experiment group }}-A_{\text {blank group }}\right) /\left(A_{\text {control group }}-A_{\text {blank group }}\right) \times 100 \%$, experiment group: with fungal stimuli, control group: without fungal stimuli, blank group: without cells and fungal stimuli.

\section{ROS assay}

RAW264.7 macrophages were washed and collected with PBS after fungal stimulation (MOI=10) as mentioned above. Macrophages were then incubated with Dihydroethidium (DHE; Beyotime, China) at $37^{\circ} \mathrm{C}$ for $30 \mathrm{~min}$. Next, fluorescence intensity was detected at $488 \mathrm{~nm}$ (excitation wavelength) and $535 \mathrm{~nm}$ (emission wavelength) through flow cytometry (Invitrogen, USA).

\section{PBMC isolation and stimulation}

With written informed consent, $20 \mathrm{~mL}$ EDTA blood samples were collected from healthy volunteers and peripheral blood mononuclear cells (PBMCs) isolation was performed by Ficoll-Paque density-gradient centrifugation. After washing and centrifuging, PBMCs were resuspended in RPMI 1640 (Gibco, USA) culture medium containing $10 \%$ FBS and then stimulated with live or heat-inactivated fungi for different durations. PMA $(25 \mathrm{ng} / \mathrm{mL})+$ ionomycin $(1 \mu \mathrm{g} / \mathrm{mL})$ stimulation for 6 hours was used as a positive control. Supernatants were then collected and stored at $-80^{\circ} \mathrm{C}$ until cytokine assays were performed. Cells from different donors were used for the biological replicates.

\section{T cell subset analysis}

PBMCs were stimulated by live conidia and hyphal fragments for 6 hours and inactivated ones for 24 hours. At the last 6 hours of incubation, PMA $(25 \mathrm{ng} / \mathrm{mL})$, ionomycin $(1 \mu \mathrm{g} / \mathrm{mL})$ and brefeldin A (10 $\mu \mathrm{g} / \mathrm{mL}$ ) (Sigma, USA) were added. Next, cells were collected and washed with PBS, followed by extracellular staining with anti-human CD3 PE-Cy7, CD4 APC-Cy7 and CD8 PE-Cy5.5 for 15 minutes. Thereafter, PBMCs were centrifuged and resuspended in Fixation/permeabilization reagents (Biogems, 
USA) for 30 minutes in order to perform the subsequent intracellular cytokine staining with anti-human IL4 R-PE, IL-17a APC and IFN-y Alexa Flour ${ }^{\text {TM }} 700$ (CD8 PE-Cy5.5: Invitrogen, USA; other antibodies:

BioLegend, USA). Cell populations were analyzed through flow cytometry. T lymphocyte was defined as $\mathrm{CD}^{+}$cells and T cell subsets were defined as Th1: $\mathrm{CD} 4^{+}$IFN- $\gamma^{+}$, Th2: $\mathrm{CD} 4^{+} \mathrm{IL}-4^{+}$and Th17: CD4 ${ }^{+} \mathrm{IL}-17 \mathrm{a}^{+}$.

\section{Mice and infection}

Forty-eight male C57BL/6 mice aged 6-8 weeks were obtained from Qinglongshan animal center (Jiangsu, China) and acclimatized. Mice were randomly divided into three groups with sixteen mice in each group (3 independent experiments). Ten mice from each group were used for survival observation, three for histopathology examination and three for RNA-seq. Chloral hydrate $(350 \mathrm{mg} / \mathrm{kg})$ was intraperitoneally injected into mice for anesthesia. The three groups were challenged intratracheally with $50 \mu \mathrm{L} \mathrm{10} / \mathrm{mL}$ hyphal fragments suspension (hyphae group), conidia suspension (conidia group) or normal saline (control group), respectively. The mice were observed every 12 hours for 10 days and their lungs were immediately removed after anesthesia. Lungs from three mice in each group were harvested and ground for RNA extraction 24 hours after fungal inoculation. In the fourth day of intervention, lungs from another three mice in each group were removed and fixed with $10 \%(\mathrm{v} / \mathrm{v})$ Formalin for periodic acid schiff (PAS) staining. All animal experiments were carried out in accordance with the Animal Care and Use Committee of Nanjing Normal University.

\section{RNA-seq}

Qualified RNA samples were digested with DNA I enzyme and then poly (A) containing mRNA was purified using Oligo(dT) containing beads. Next, mRNA was fragmented and reverse transcribed to firstand second-strand. Double-strand DNA ends were repaired and modified. Then DNA was amplified via PCR and the products were thermally denatured into single-stranded and cyclized. After rolling circle amplification and quality control, high-throughput sequencing was performed at the BGISEQ platform and base calling was used for raw reads transformation.

\section{Real-Time Reverse Transcriptase Polymerase Chain Reaction (qRT-PCR)}

Total RNA was isolated from RAW264.7 cells or murine lung tissues by using TRIzol reagent (Invitrogen, USA) according to the instructions. $1 \mu \mathrm{g}$ RNA was reverse-transcribed into cDNA template and cDNA products were diluted 1:5 with diethylpyrocarbonate-treated water. Real-Time polymerase chain reaction (20 $\mu \mathrm{L}$ reaction volume) was performed using a $2 \mu \mathrm{L}$ cDNA aliquot and $10 \mu \mathrm{L}$ TB Green ${ }^{\circledR}$ Premix Ex TaqTM II (Takara, China). $\beta$-actin was used as an internal control. The primers were exhibited in Table 1.

\section{The measurement of cytokines by ELISA}

Supernatants of macrophages and PBMCs were collected after stimulation and centrifuged for enzymelinked immunosorbent assay (ELISA). Commercially available ELISA kits for mouse TNF-a, IL-6 and human TNF-a, IL-6, IL-1b, IL-4 (Novusbio, USA) were used according to the manufacturers' instructions. 


\section{Data analysis}

Analysis of flow cytometric samples was performed in FlowJo software (TreeStar, USA). Statistical analyses were performed in GraphPad Prism 7 (GraphPad Software Inc., USA). One- or two-way analysis of variance (ANOVA) was used to analyze datasets of CCK-8, qRT-PCR and ELISA depending on the number of explanatory variables in the experimental design. Results were presented as mean \pm standard deviation (SD) of triplicate experiments. Flow cytometry results about T cell populations were analyzed by Friedman test. $P<0.05$ was considered statistically significant.

\section{Results}

\section{Macrophages RAW264.7 were classically activated by $A$. fumigatus conidia and produced more ROS than hyphae stimulation}

To elucidate the different responses of macrophages against conidia or hyphae, cells were incubated with the moulds. Above all, we found that in the conidia-incubated cells, the expression of iNOS gradually increased within 24 hours (Fig.1a), which meant that macrophages were classically activated (M1 polarization). Based on this, we determined the best co-incubation duration for subsequent experiments, 6 hours for live fungi and 24 hours for inactivated ones. Moreover, the conidia-incubated macrophages showed a concentration-dependent enhancement of M1 polarization (Fig.1b).

In host defense against fungi like alveolar macrophages, reactive oxygen species (ROS) plays an essential role. In this study, intracellular superoxide $\left(\mathrm{O}^{-}\right)$were detected by DHE staining. Macrophages stimulated by conidia revealed a higher production of ROS compared with the control and hyphae group (Fig.1d,1e), which was consistent with the cellular iNOS levels.

\section{Fungal stimulation promotes the proliferation of macrophages RAW264.7}

CCK-8 assay was used to measure the cell viability after fungal stimulation. Both conidia and hyphal fragments stimulation exhibited a concentration-dependent rise in the cell proliferation $(P<0.05)$, and the live fungi groups showed a more obvious alteration than the inactivated ones $(P<0.05)$, though no significant difference was found between conidia and hyphae groups ( $P>0.05)$ (Fig.1c).

\section{Cytokine profile of $A$. fumigatus stimulated macrophages RAW264.7}

Cytokine profile can intuitively reflect inflammatory reactions of macrophages after different mould particles exposure. As is shown in the Fig.2, the overall secretion trends of TNF- $a$ and IL- 6 were concentration-dependent rises, though excessive hyphae exposure could lead to secretion suppression sometimes. The cytokine levels of macrophages stimulated by heat-inactivated fungi were higher than live ones because of different incubation times. Hyphal fragments triggered remarkable releases of TNF-a and IL- 6 in both live and inactivated fungal groups. In contrast, minor elevation of cytokines was found after exposing to live conidia for 6 hours. Heat-inactivated conidia induced a remarkably high level of 
TNF-a release only in the highest concentration (MOI 100) after 24-hour exposure, while IL-6 secretion had been already markedly elevated in a relative lower concentration of stimulation.

\section{Cytokine profile of $A$. fumigatus stimulated PBMCs}

PBMCs include monocytes and lymphocytes. Cytokine profile of PBMCs induced by $A$. fumigatus conidia and hyphal fragments exhibited a further insight into the host immune response. The overall secretion trends of all the cytokines including human TNF-a, IL-6, IL-4 and IL- $1 \mathrm{~b}$ were increases along with stimuli concentration (Fig.2), which were similar to cytokine profile of macrophages. In most cases, the cytokine concentration of hyphae-incubated PBMCs was higher than that of conidia-incubated cells at the same fungal concentration.

\section{Dynamic $\mathrm{T}$ cell subset changes induced by conidia and hyphae}

PBMCs exposed to conidia or hyphae were significantly different in T cell subsets (Fig.3). In general, hyphae-incubated cells showed an obvious elevation of CD4/CD8 ratio compared with that of conidiaincubated ones $(P<0.05)$, with the percentage of $\mathrm{CD} 4^{+}$significantly increasing $(P<0.05)$ and $\mathrm{CD} 8^{+}$slightly decreasing ( $P>0.05)$. The percentage of helper T cell 1 (Th1\%) increased greatly in both LC and HIC group $(P<0.05)$. On the contrary, Th1\% showed no significant change in either of hyphae group, despite the overall average of Th1\% for four donors decreased sharply in HIH group ( $P>0.05)$. In terms of helper T cell 2 (Th2 cell), hyphae group exhibited a higher proportion compared with corresponding conidia group, though the result did not reach statistical significance ( $P>0.05)$. Neither group showed any change in helper T cell 17 (Th17) cell differentiation ( $P>0.05)$.

\section{Survival of immunocompetent C57BL/6 mice following inhalation of $A$. fumigatus conidia or hyphal fragments}

In murine pulmonary aspergillosis model, the mortality of hyphae-inoculated immunocompetent mice reached $40 \%$, while the mice inoculated with conidia and normal saline all survived to the end point of the assay (Fig.4a). The result was consistent with the previous report of Zhang et a[21]. In addition, amongst all sections made, focal infection of aspergillus was only observed on the pulmonary histopathology of hyphae-inoculated mice 4 days post inoculation (Fig.4b). And positive result about fungal culture of murine lungs also confirmed the aspergillosis.

\section{The immune responses against hyphae and conidia has similarities and differences in murine pulmonary aspergillosis model}

A total of 18,992 transcripts were detected by RNA-seq. Among three groups, the difference of expression between control and conidia group was relatively smaller, with only 705 genes significantly differentially regulated $\left(\left|\log _{2} F C\right| \geq 1\right.$, Qvalue $\left.\leq 0.05\right)$. On the contrary, the number of differentially expressed genes (DEGs) between hyphae and control group was up to 3977, with 1839 up-regulated and 2138 downregulated (Fig.5a). However, 2893 significant DEGs (Fig.5a, b) between conidia and hyphae group were 
focused to analyze. KEGG pathway enrichment analysis showed a series of immunologically relevant pathways were involved, including NOD-like receptor (NLR) signaling pathway, NF-kappa B signaling pathway, TNF signaling pathway and others (Fig.5c). In addition, KEGG pathway classification revealed that signal transduction and immune system were top2 DEGs-intensive categories (Fig.5d).

Further analysis demonstrated that both hyphae and conidia could induce a series of inflammatory responses in murine lungs, but host defense against hyphae was much more intensive. Immunologically relevant pathways mentioned above were activated in both groups, but associated genes expressed more strongly in hyphae group. We subsequently identified a series of differentially expressed essential receptor genes including TLRs, Clecs and NLRs to gain insight into immune responses against aspergillus (Fig.6).

Thereafter, to better understand about immune signaling patterns amongst the murine model, $\mathrm{T}$ cell differentiation pathways associated genes were analyzed by qRT-PCR. As is shown in Fig.7, Th17 cell differentiation pathway tended to be activated after intratracheal mould injection in both groups. We found that relative expressions of IL-17a, IL-17f and stat3 were up-regulated. Besides, expressions of IL17 signaling associated chemokines CXCL1, CXCL2, CXCL5, CXCL10, and CCL2 were likewise significantly increased. When it comes to Th1 and Th2 cell differentiation, RNA-seq revealed that Th2 cell differentiation tended to get activated and Th1 differentiation relatively silenced in hyphae group. The genes related to Th2 cell differentiation including IL-13 and IL-4Ra, were significantly up-regulated while the key genes in Th1 cell differentiation pathway such as stat1and T-bet were down-regulated. However, in conidia group, gene expressions of Th1 and Th2 cell differentiation pathways were not significantly altered except the mild elevation of IL-4Ra, which was not consistent with the result of experiment in vitro. We speculated that the phenomenon might be ascribed to the effective anatomical elimination of conidia in immunocompetent host and only a small portion of them escaped to challenge subsequent immune system[16, 24]. Moreover, Th1 and Th17 cells showed antagonistic action against each other and activation of IL-17 signaling would suppress Th1 cell differentiation[25]. The slight increase of IL-4Ra was speculated may be attributed to the conidia germination over time.

\section{Discussion}

A. fumigatus, the causative agent of a series of infections in human, is a kind of ubiquitous fungus in the environment. IPA is the most dangerous and fatal type of aspergillosis, which has already raised great concern in clinicians and researchers. Moreover, COVID-19 is now prevalent all over the world, causing millions of infections. A high proportion of severe influenza patients present with acute respiratory distress syndrome and need intensive care. Dysfunction of immune system and prolonged hospitalization inevitably induce these patients suffering from high-risk of secondary fungal infections[26]. Aspergillus co-infection has been reported frequently and coronavirus associated pulmonary aspergillosis is usually associated with worsening conditions and causes increased mortality $[12,13]$. Therefore, more efforts should be made to clarify the interaction between $A$. fumigatus and host immunity. 
This research is based on Zhang's experimental results which has published in 2020[21], as mentioned above. In general, the host immune responses induced by $A$. fumigatus conidia and hyphae are distinctly different. Various PAMPs on the surface of hyphae and conidia can be recognized by specific PRRs of immunocytes, activating downstream intracellular signal transduction pathways and different inflammatory responses[15]. Previous studies have revealed that both hyphae and conidia of $A$. fumigatus can activate TLR2-related cytokine synthesis, but TLR4-related pathways can only be induced by conidia[27]. In addition, both dendritic cell-associated C-type lectin-1 (dectin-1) and lectin-2 (dectin-2) receptor can recognize swollen conidia and hyphae to induce host immune responses, but neither can recognize resting conidia[28, 29].

In this study, we confirmed that hyphae of $A$. fumigatus could induce stronger host immune responses than conidia. Live conidia gradually swelled and germinated during the 6-hour incubation, transforming to the hyphae state. As mentioned above, the PAMPs on the surface of conidia underwent tremendous changes during the process. Therefore, we carried out incubation of inactivated fungi with immunocytes and extended the experimental time to 24 hours to verify the accumulated immunological differences induced by conidia and hyphae. Thereafter, the results of live and inactivated fungi stimulation were similar, though the immunological differences about cytokine secretions and T cell differentiation between inactivated ones were larger, which were probably attributed to extended time of incubation. In murine model, we validated the fact again that immunologically relevant genes and pathways were activated more significantly in hyphae group than conidia group.

Macrophages are now known to be a decisive part of innate immunity to resist the infection from $A$. fumigatus. Both iNOS and ROS levels are important markers of host immunity, which were significantly higher in conidia-incubated macrophages than that of hyphae-incubated cells and control cells. iNOS was mainly induced in macrophages and nitric oxide (NO) produced by iNOS would be scavenged to generate ROS, leading to extra ROS production[30]. Besides, macrophage polarization is an essential symbol to distinguish its functions. M1 macrophages are generally found to be polarized by lipopolysaccharide or Th1 associated cytokines[31]. As a feedback, M1 macrophages can direct T cells towards Th1 through IL12 and antigen presentation. Subsequent analysis of flow cytometry indicated that the conidia-incubated PBMCs expressed higher levels of IFN-y (Th1 signaling), which was consistent with the macrophage polarization state.

Unlike macrophages, $T$ lymphocytes are an indispensable part of adaptive immunity. In regard to $T$ cell subset change, we should first take great concern about the changes of $\mathrm{CD} 4^{+}$and $\mathrm{CD} 8^{+} \mathrm{T}$ cell populations. The percentage of $\mathrm{CD} 8^{+} \mathrm{T}$ cells tended to get down after hyphae stimulation, which usually indicated a poor prognosis in IPA patients[32]. Therefore, we speculate that the decrease of $\mathrm{CD}^{+} \mathrm{T}$ cell proportion in severe IPA patients is likely to be owing to the overgrowth of invasive hyphae at late stage of infection, which can hardly be eliminated by cytotoxic $\mathrm{CD} 8^{+} \mathrm{T}$ cells. In terms of $\mathrm{CD} 4^{+} \mathrm{T}$ cells, cell differentiation clearly reflected its functions. Th1 signaling drives to fight virus, bacteria and other intracellular infections, such as $A$. fumigatus conidia while Th2 signaling leads to defend extracellular organisms. Th1/Th2 are in a dynamic balance and over-activation of either pathway can down-regulate 
the other[33]. Besides, Th17 also plays an important role in host defense against micro-organisms, which is associated with neutrophils migration and increased inflammation[34]. To summarize the in vitro and in vivo experiments results, it comes to the conclusion that conidia stimulation tends to promote Th1 cell differentiation, while hyphae stimulation leads to the opposite result as well as activates Th2 cell differentiation. Furthermore, both conidia and hyphae could activate IL-17 signaling pathway, which may make a dual-directional regulation related to antifungal immune resistance[16].

It's a sophisticated orchestration for the innate and adaptive immunity to provide protection from fungal invasion. As for the explanation of initial phenomenon, to some extent, it's a paradox that hyphal fragments successfully constructed the aspergillosis model rather than conidia despite the fact that hyphae induced more potent inflammation. The host immune responses induced by conidia played a better protective role. In fact, there are various effective ways to eliminate conidia by host immunity, from anatomical barrier to the synergistic action of multiple immune cells[16]. However, the hyphae are too large to get internalized and can hardly be cleared. Even neutrophil extracellular traps (NETs), an effective form of neutrophil-mediated antimicrobial defense, can just inhibit hyphal growth instead of killing hyphae[16]. Moreover, hyphae invasion tends to activate Th2 cell differentiation, which is known for its suppressive function in immunity and usually leads to unfavorable outcomes[35].

To summarize, hyphae state is a neglected pathogenetic form of aspergillosis. We conducted a preliminary exploration about immune response against hyphae through in vivo and in vitro experiments, and confirmed the different host defense against hyphae and conidia. However, the underlying mechanism of the immunological differences remains unclear and more studies are required to clarify it for new preventive measures.

\section{Declarations}

Acknowledgments We thank Dr. Weida Liu and his team in the Department of Medical Mycology, Institute of Dermatology, Chinese Academy of Medical Science and Peking Union Medical College for their help to the experiment.

Funding This work was financially supported by the National Natural Science Foundation of China (NSFC) [grant number 81871630 and 81330035 ].

Competing Interest The authors have no competing interest to declare.

Ethical approval The study was approved by the ethics committee of Jinling Hospital (2015NJKY-035-02) and the Animal Care and Use Committee of Nanjing Normal University (20200703).

Informed consent All volunteers the blood samples obtained from knew their rights and gave informed consents.

Author contributions $Y L, H S$ and $Y S$ contributed to the study conception and design. YL and JX performed the experiments; YL, FL and QK analyzed and interpreted results; $Y L$ wrote the first draft of the 
manuscript; FL reviewed; and all authors contributed and approved the final version of the manuscript.

\section{References}

1. Chabi ML, Goracci A, Roche N, Paugam A, Lupo A, Revel MP (2015) Pulmonary aspergillosis. Diagn Interv Imaging 96 (5):435-442

2. Gao Y, Soubani A (2020) Advances in the diagnosis and management of pulmonary aspergillosis. Adv Respir Med 87 (6):231-243

3. Kanj A, Abdallah N, Soubani AO (2018) The spectrum of pulmonary aspergillosis. Respir Med 141:121-131

4. Kosmidis C, Denning DW (2014) The clinical spectrum of pulmonary aspergillosis. Thorax 70 (3):270-277

5. Bassetti M, Garnacho-Montero J, Calandra T, et al. (2017) Intensive care medicine research agenda on invasive fungal infection in critically ill patients. Intensive Care Med 43 (9):1225-1238

6. Shorr AF, Spalding JR, Harrington R, Nathanson BH, Zilberberg MD (2018) Epidemiology and Outcomes of Hospitalizations With Invasive Aspergillosis in the United States, 2009-2013. Clin Infect Dis 67 (5):727-735

7. Tarka P, Nitsch-Osuch A, Gorynski P, Tyszko P, Bogdan M, Kanecki K (2019) Epidemiology of Pulmonary Aspergillosis in Hospitalized Patients in Poland During 2009-2016. Adv Exp Med Biol 1160:73-80

8. Tavakoli M, Yazdani Charati J, Hedayati MT, Moosazadeh M, Badiee P, Seyedmousavi S, Denning DW (2019) National trends in incidence, prevalence and disability-adjusted life years of invasive aspergillosis in Iran: a systematic review and meta-analysis. Expert Rev Respir Med 13 (11):11211134

9. Bartoletti M, Pascale R, Cricca M, et al. (2020) Epidemiology of invasive pulmonary aspergillosis among COVID-19 intubated patients: a prospective study. Clin Infect Dis

10. Borman AM, Palmer MD, Fraser M, et al. (2020) COVID-19-Associated Invasive Aspergillosis: Data from the UK National Mycology Reference Laboratory. J Clin Microbiol 59 (1)

11. Lai CC, Yu WL (2020) COVID-19 associated with pulmonary aspergillosis: A literature review. J Microbiol Immunol Infect

12. Nasir N, Farooqi J, Mahmood SF, Jabeen K (2020) COVID-19-associated pulmonary aspergillosis (CAPA) in patients admitted with severe COVID-19 pneumonia: An observational study from Pakistan. Mycoses 63 (8):766-770

13. Salehi M, Ahmadikia K, Badali H, Khodavaisy S (2020) Opportunistic Fungal Infections in the Epidemic Area of COVID-19: A Clinical and Diagnostic Perspective from Iran. Mycopathologia 185 (4):607-611

14. Wu Z, McGoogan JM (2020 Apr 7) Characteristics of and Important Lessons From the Coronavirus Disease 2019 (COVID-19) Outbreak in China: Summary of a Report of 72314 Cases From the 
Chinese Center for Disease Control and Prevention. JAMA 323(13):1239-1242

15. van de Veerdonk FL, Gresnigt MS, Romani L, Netea MG, Latge JP (2017) Aspergillus fumigatus morphology and dynamic host interactions. Nat Rev Microbiol 15 (11):661-674

16. Margalit A, Kavanagh K (2015) The innate immune response to Aspergillus fumigatus at the alveolar surface. FEMS Microbiol Rev 39 (5):670-687

17. Jean-Paul Latge' AB, Georgios Chamilos (2017) The Cell Wall of the Human Fungal Pathogen Aspergillus fumigatus: Biosynthesis, Organization, Immune Response, and Virulence. Annu Rev Microbiol 71:99-116

18. Afanou KA, Straumfors A, Skogstad A, et al. (2015) Profile and Morphology of Fungal Aerosols Characterized by Field Emission Scanning Electron Microscopy (FESEM). Aerosol Sci Technol 49 (6):423-435

19. Afanou KA, Straumfors A, Skogstad A, et al. (2014) Submicronic fungal bioaerosols: high-resolution microscopic characterization and quantification. Appl Environ Microbiol 80 (22):7122-7130

20. Dufresne PJ, Moonjely SS, Ozaki K, Tremblay C, Laverdière M, Dufresne SF (2017) High frequency of pathogenicAspergillusspecies among nonsporulating moulds from respiratory tract samples. Med Mycol 55 (2):233-236

21. Zhang Z, Jiang Y, Chen J, Chen P, Kong Q, Lu L, Sang H (2020) In vitro and in vivo characterization of two nonsporulating Aspergillus fumigatus clinical isolates from immunocompetent patients. Med Mycol 58 (4):543-551

22. Øya E, Solhaug A, Bølling AK, Øvstebø R, Steensen TB, Afanou AKJ, Holme JA (2019) Proinflammatory responses induced by $A$. fumigatus and $A$. versicolor in various human macrophage models. J Toxicol Environ Health A 82 (8):483-501

23. Zhang C, Kong Q, Cai Z, et al. (2015) The newly nonsporulated characterization of an Aspergillus fumigatus isolate from an immunocompetent patient and its clinic indication. Fungal Genet Biol $81: 250-260$

24. Latge JP, Chamilos G (2019) Aspergillus fumigatus and Aspergillosis in 2019. Clin Microbiol Rev 33 (1)

25. Zelante T, De Luca A, Bonifazi P, et al. (2007) IL-23 and the Th17 pathway promote inflammation and impair antifungal immune resistance. Eur J Immunol 37 (10):2695-2706

26. Mohamed A, Rogers TR, Talento AF (2020) COVID-19 Associated Invasive Pulmonary Aspergillosis: Diagnostic and Therapeutic Challenges. J Fungi (Basel) 6 (3)

27. Mihai G Netea AW, Jos W M Van der Meer,Matthew J Fenton,Trees J G Verver-Janssen,Liesbeth E H Jacobs,Tonje Andresen,Paul E Verweij,Bart Jan Kullberg (2003 Jul 15) Aspergillus fumigatus evades immune recognition during germination through loss of toll-like receptor-4-mediated signal transduction. J Infect Dis 188(2):320-6

28. Geoffrey M. Gersuk DMU, Liqun Zhu and Kieren A. Marr (2006) Dectin-1 and TLRs Permit Macrophages to Distinguish between Different Aspergillus fumigatus Cellular States. J Immunol 176:3717-3724 
29. Sun H, Xu XY, Tian XL, et al. (2014) Activation of NF-kappaB and respiratory burst following Aspergillus fumigatus stimulation of macrophages. Immunobiology 219 (1):25-36

30. Yan M, Hou M, Liu J, Zhang S, Liu B, Wu X, Liu G (2017) Regulation of iNOS-Derived ROS Generation by HSP90 and Cav-1 in Porcine Reproductive and Respiratory Syndrome Virus-Infected Swine Lung Injury. Inflammation 40 (4):1236-1244

31. Mills CD (2015) Anatomy of a discovery: $\mathrm{m} 1$ and $\mathrm{m} 2$ macrophages. Front Immunol 6:212

32. Na Cui HW, Yun Long,Dawei Liu (2013 Jul 24) CD8+ T-cell counts: an early predictor of risk and mortality in critically ill immunocompromised patients with invasive pulmonary aspergillosis. Crit Care 17(4):R157

33. Kidd P (2003 Aug) Th1/Th2 balance: the hypothesis, its limitations, and implications for health and disease. Altern Med Rev 8(3):223-46

34. Wilson NJ, Boniface K, Chan JR, et al. (2007) Development, cytokine profile and function of human interleukin 17-producing helper T cells. Nat Immunol 8 (9):950-957

35. Holger Hebart CB, Paul Fisch, Jacqueline Sarfati, Christoph Meisner, Manuela Baur, Jürgen Loeffler, Michel Monod, Jean-Paul Latgé, Hermann Einsele (2002 Dec 15) Analysis of T-cell responses to Aspergillus fumigatus antigens in healthy individuals and patients with hematologic malignancies. Blood 100(13):4521-8

\section{Tables}

Table 1. Primer sequences. 


\begin{tabular}{|c|c|}
\hline Primers & Sequences $5^{\prime} \rightarrow 3^{\prime}$ \\
\hline$\beta$-actin F & CATTGCTGACAGGATGCAGAAGG \\
\hline$\beta$-actin R & TGCTGGAAGGTGGACAGTGAGG \\
\hline iNOS F & GGAGTGACGGCAAACATGACT \\
\hline iNOS R & TCGATGCACAACTGGGTGAAC \\
\hline T-bet $F$ & AGCAAGGACGGCGAATGTT \\
\hline T-bet R & GGGTGGACATATAAGCGGTTC \\
\hline stat1 $\mathrm{F}$ & GCTGCCTATGATGTCTCGTTT \\
\hline stat1 R & TGCTTTTCCGTATGTTGTGCT \\
\hline IL-4Ra F & TGGATCTGGGAGCATCAAGGT \\
\hline IL-4Ra R & TGGAAGTGCGGATGTAGTCAG \\
\hline IL-13 F & CAGCCTCCCCGATACCAAAAT \\
\hline IL-13 R & GCGAAACAGTTGCTTTGTGTAG \\
\hline stat3 F & AGCTGGACACACGCTACCT \\
\hline stat3 R & AGGAATCGGCTATATTGCTGGT \\
\hline IL-17a F & TTTAACTCCCTTGGCGCAAAA \\
\hline IL-17a R & СTTTCCCTCCGCATTGACAC \\
\hline IL-17f F & TGCTACTGTTGATGTTGGGAC \\
\hline IL-17f R & CAGAAATGCCCTGGTTTTGGT \\
\hline TNF-a F & CAGGCGGTGCCTATGTCTC \\
\hline TNF-a R & CGATCACCCCGAAGTTCAGTAG \\
\hline IL-6 F & TAGTCСTTССТАССССААТTTCC \\
\hline \multicolumn{2}{|l|}{ IL-6R } \\
\hline IL-6 R & TTGGTCCTTAGCCACTCCTTC \\
\hline IL-1b F & GCAACTGTTCCTGAACTCAACT \\
\hline IL-1b R & ATCTTTTGGGGTCCGTCAACT \\
\hline
\end{tabular}

Figures 
$\mathbf{a}$

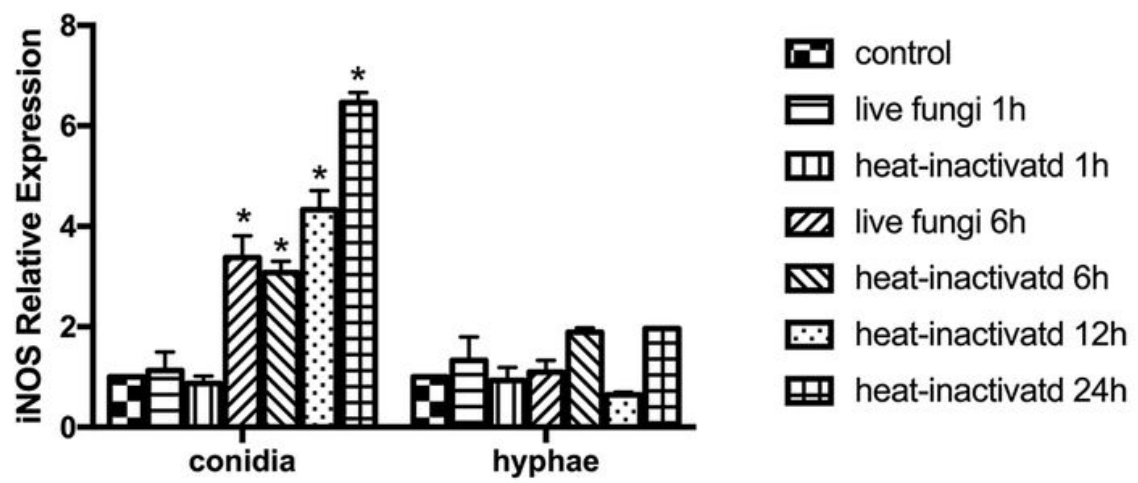

b

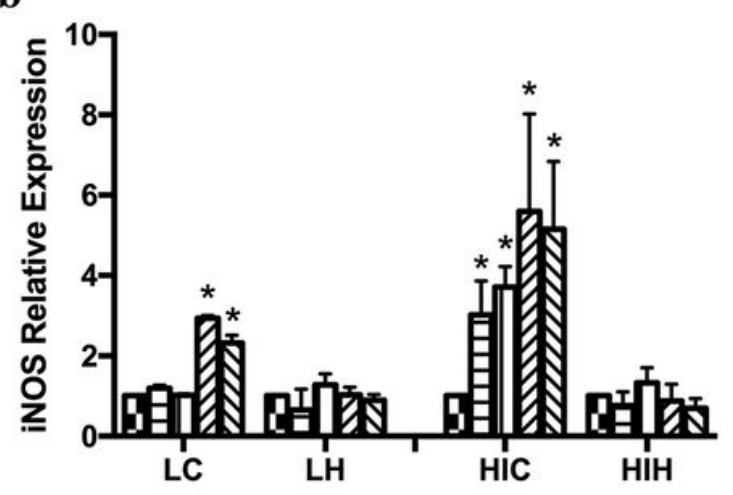

c

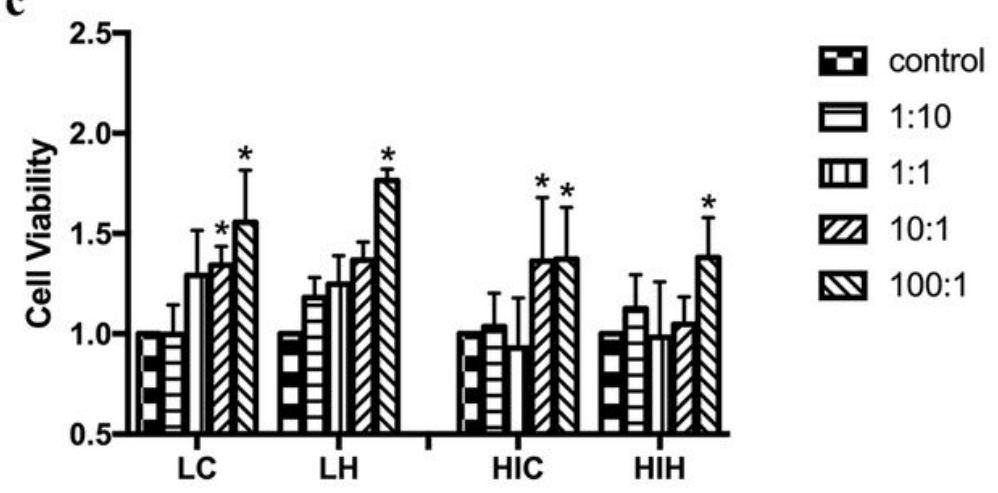

d

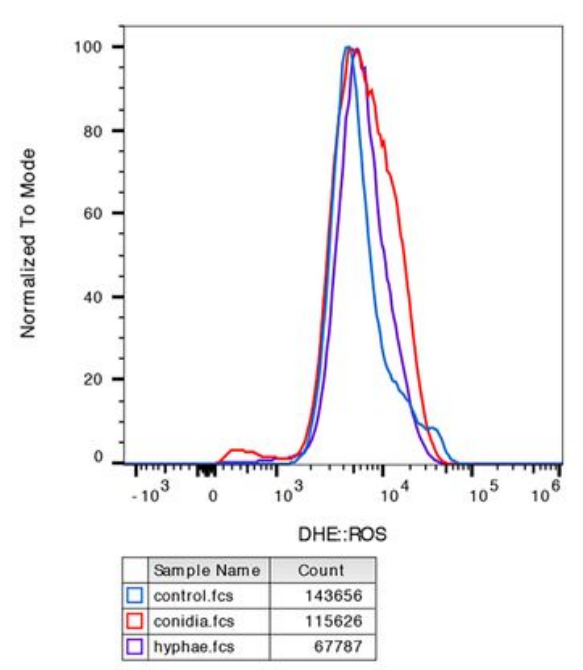

e

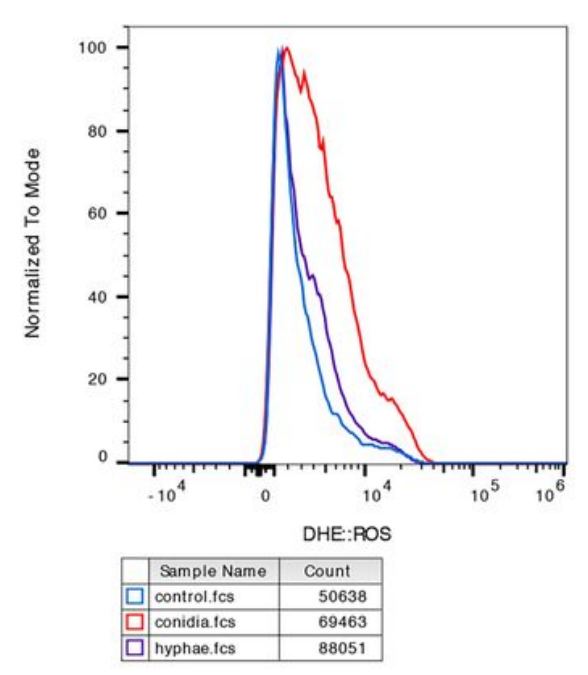

\section{Figure 1}

Immune responses of macrophages induced by A. fumigatus. (a) The change of iNOS relative expression over time. iNOS relative expression (b) and cell viability (c) of macrophages were significantly changed after stimulating by moulds of different concentrations ( $\mathrm{MOI}$ ranging from 0.1 to 100). A. fumigatus conidia induced more ROS production in macrophages compared with hyphae. RAW264.7 cells were stimulated by live (d) and heat-inactivated (e) fungi, respectively. ${ }^{*} \mathrm{P}<0.05$ vs the control group. 
a

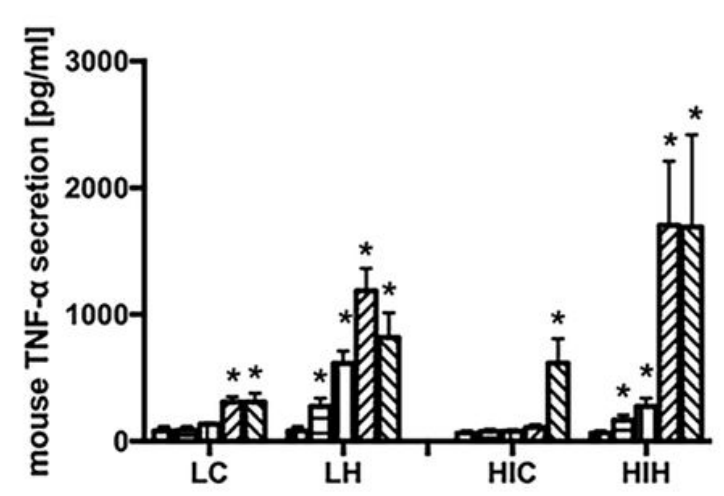

c

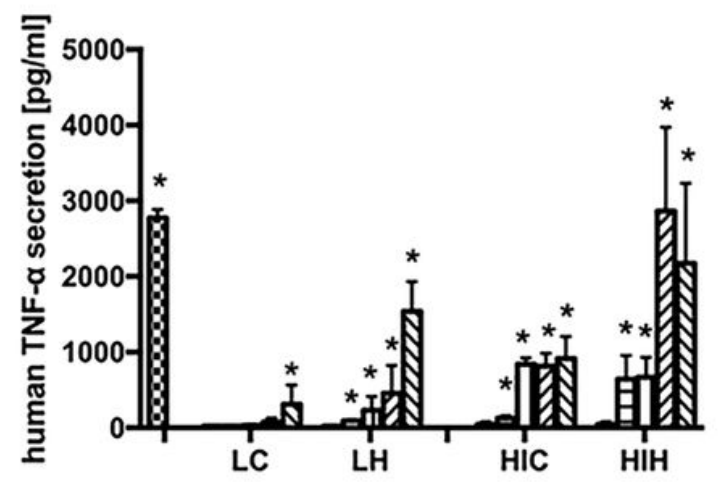

e

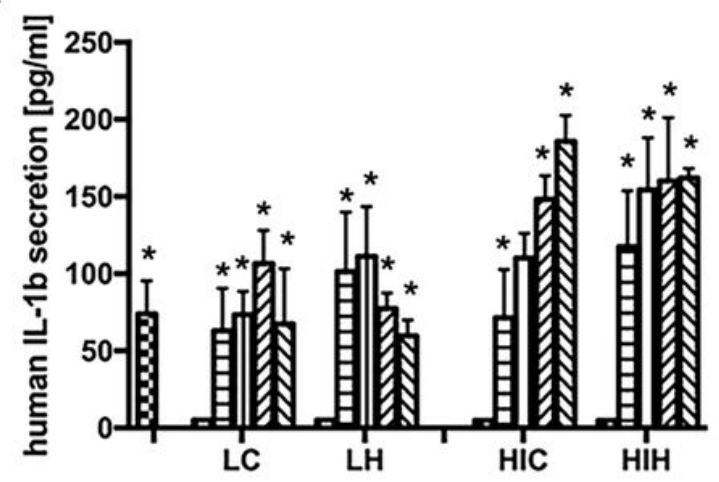

b

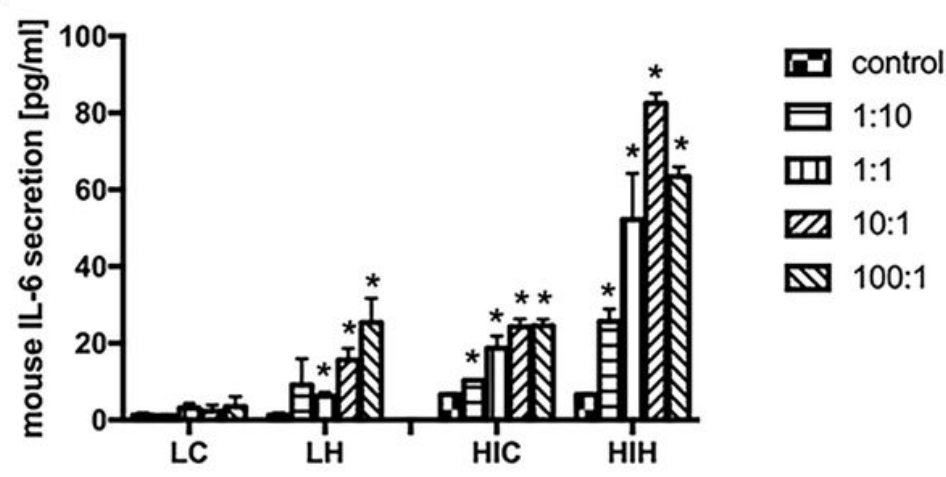

d

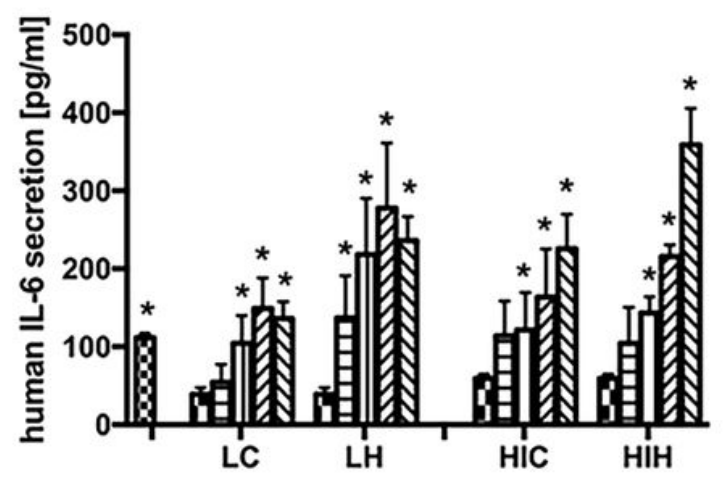

W PMAlonomycin

ㅁ. control

曰 1:10

미 1:1

[2] 10:1

100:1

\section{f}

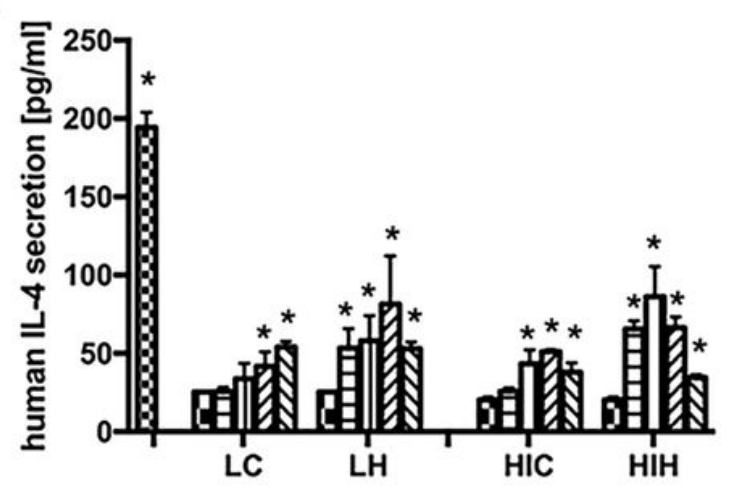

B PMAlonomycin

므 control

曰 1:10

미 1:1

[2] 10:1

피 100:1

Figure 2

Cytokine profile of A. fumigatus stimulated macrophages and PBMC. Macrophage releases of TNF-a (a) and IL- 6 (b) and PBMC releases of TNF-a (c), IL-6 (d), IL-1b (e) and IL-4 (f) were measured by ELISA after exposing to different concentrations of conidia and hyphal fragments. ${ }^{*} \mathrm{P}<0.05$ vs the control group. 
CD4
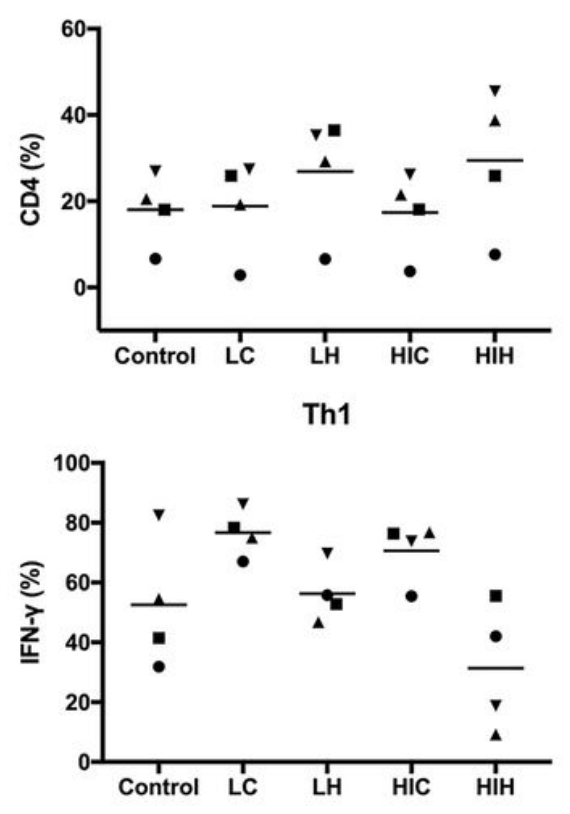

CD8
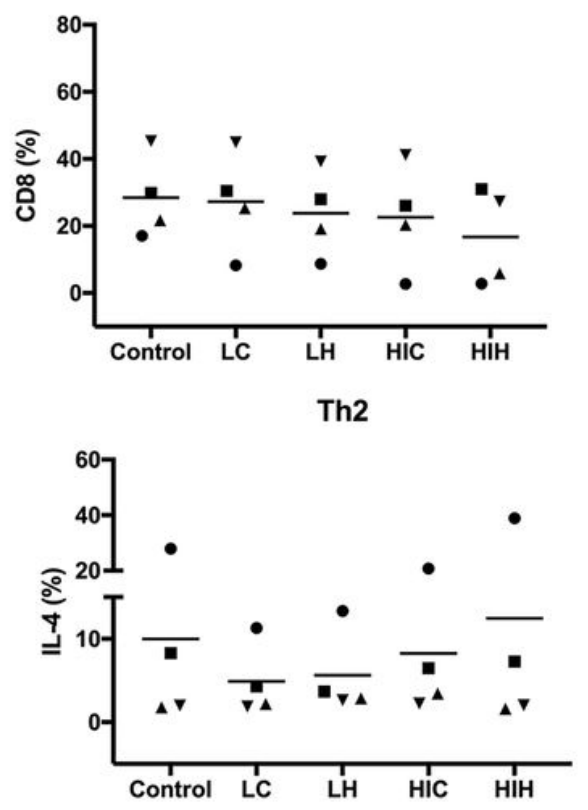

CD4/CD8
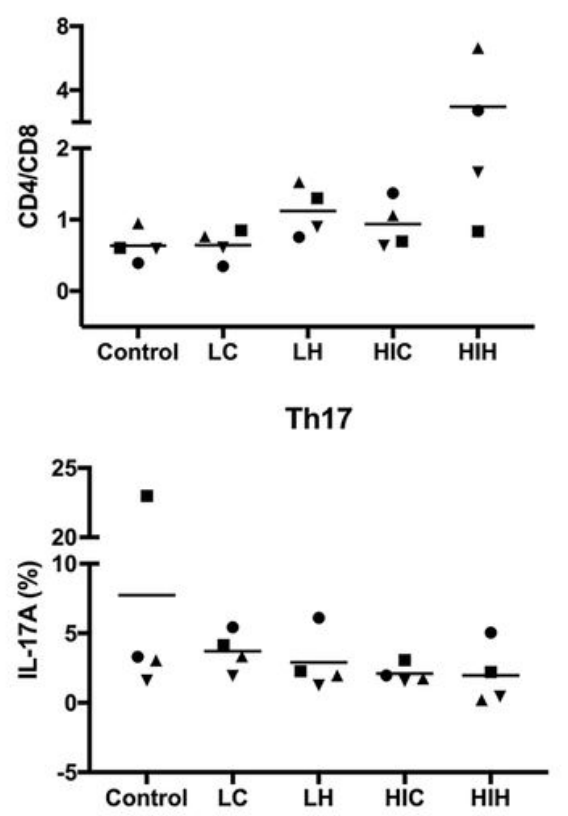

Figure 3

T cell population changes after stimulating by A. fumigatus. PBMCs were donated from four healthy volunteers. Each symbol represents one donor. Horizontal bars indicate arithmetic means. Friedman test demonstrated that Th1\%, CD4\% and CD4/CD8 ratio altered significantly $(P<0.05) . C D 4(\%)=C D 4+/ C D 3+$, CD8(\%)=CD8+/CD3+, Th1(\%)=IFN-y+/CD4+, Th2(\%)=IL-4+/CD4+, Th17(\%)=IL-17a+/CD4+. 
a

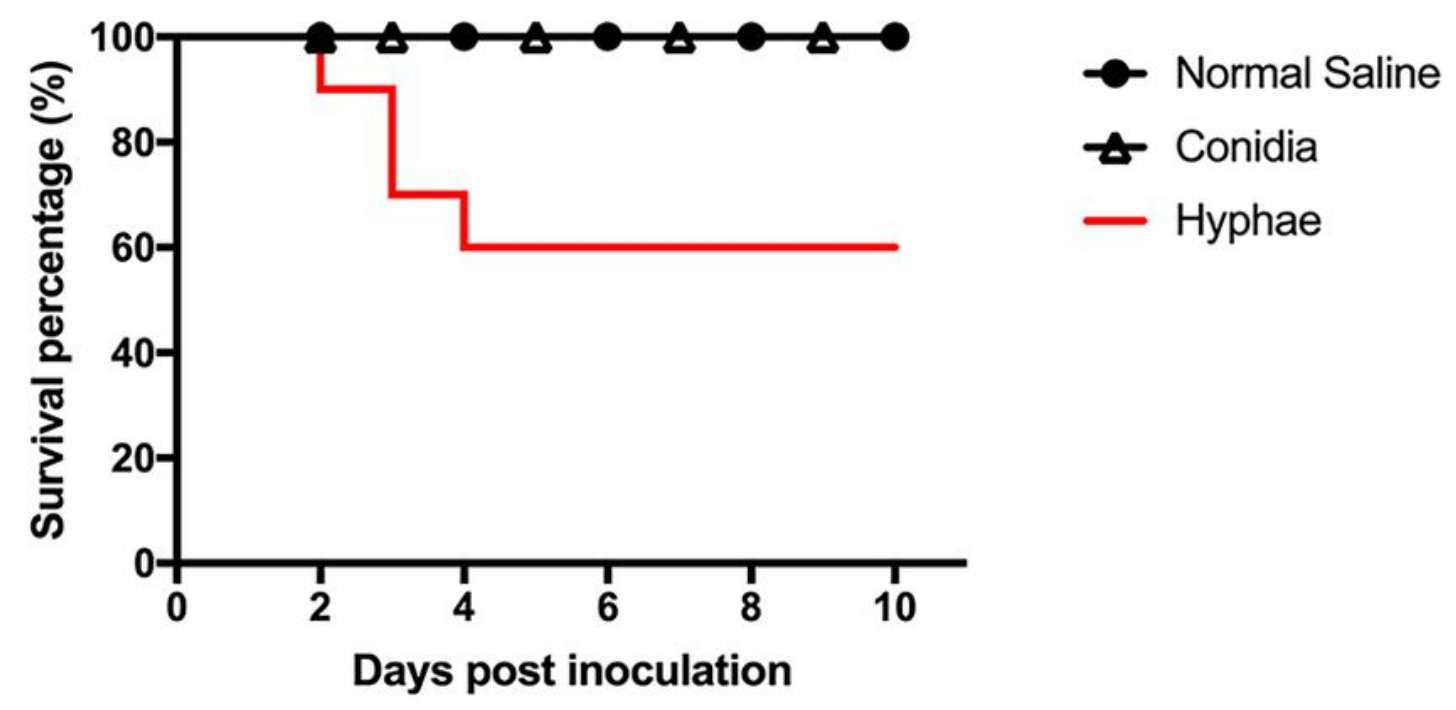

b

Control
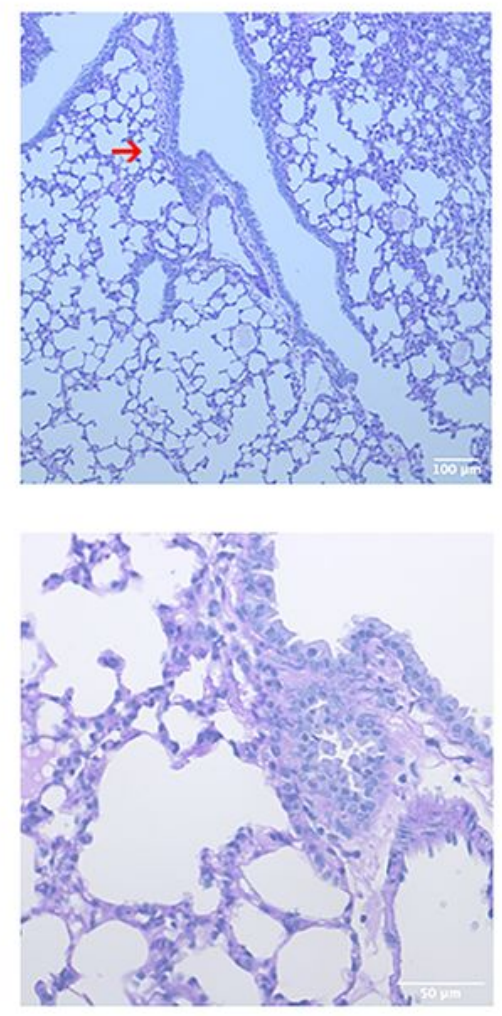

Conidia
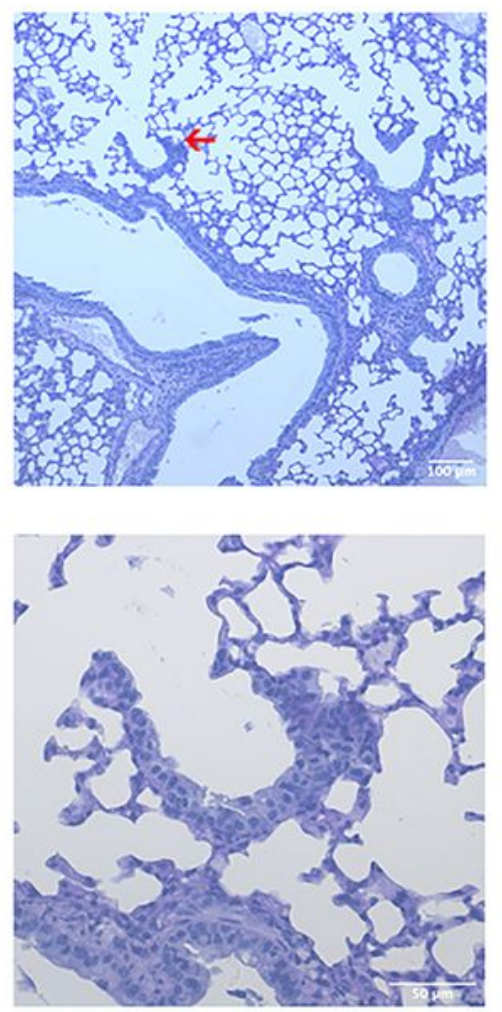

Hyphae
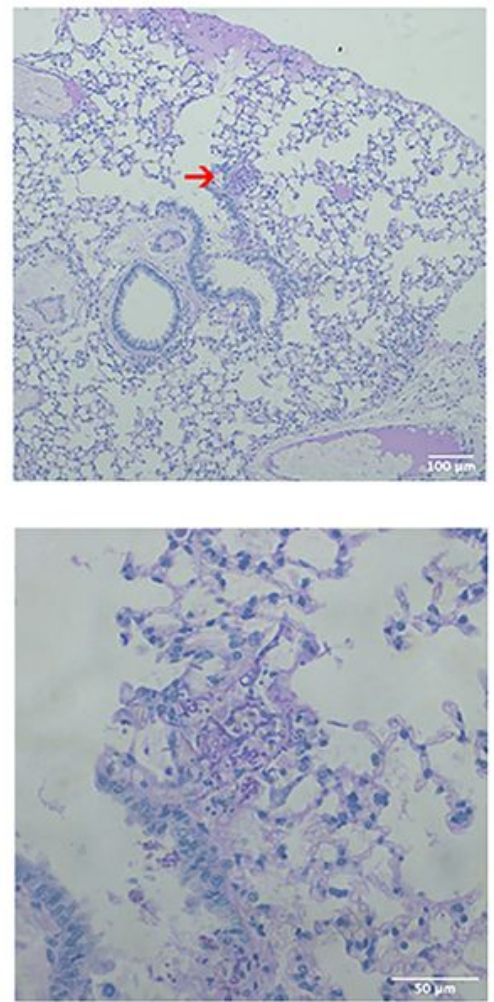

\section{Figure 4}

Murine pulmonary aspergillosis model. (a) The survival curves of mice inoculated with normal saline, conidia and hyphal fragments. Hyphae of A. fumigatus rather than conidia successfully constructed pulmonary aspergillosis in immunocompetent mice. (b) Photographs of PAS stained lung sections of mice that were killed 4 days post inoculation. Pictures of upper line are 100x magnified, and the lower ones are $400 \times$ magnified. 
a

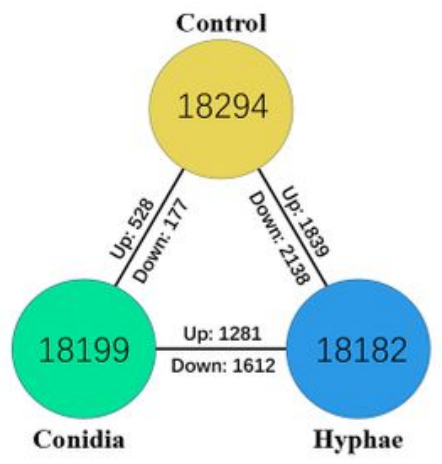

c

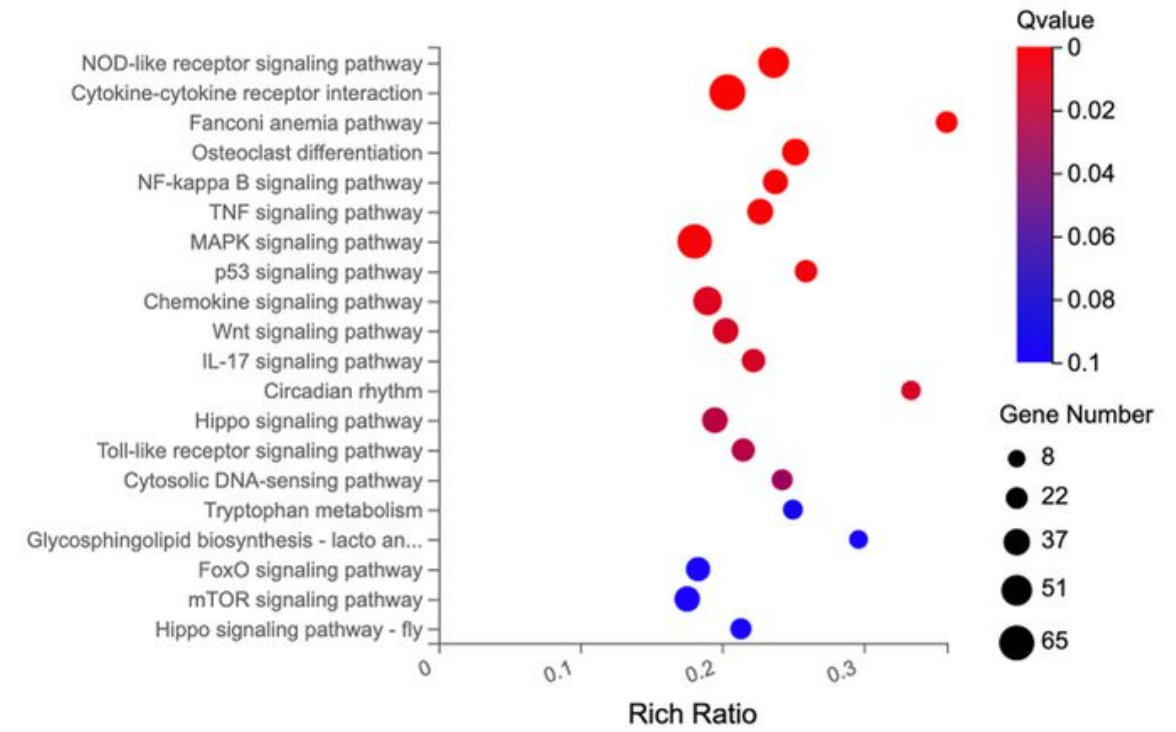

b

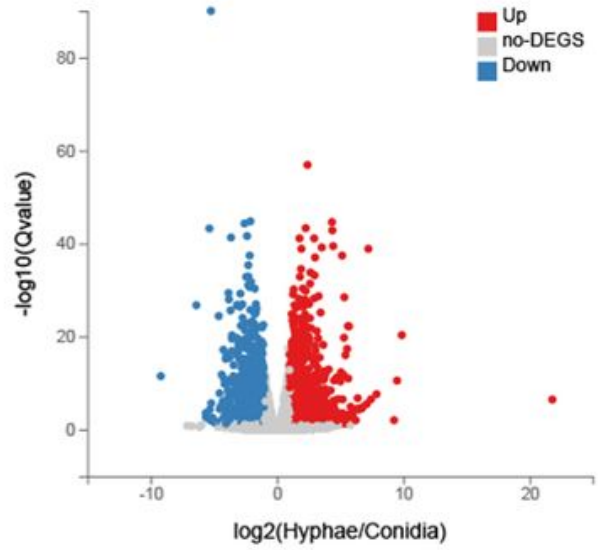

ich Ratio

d

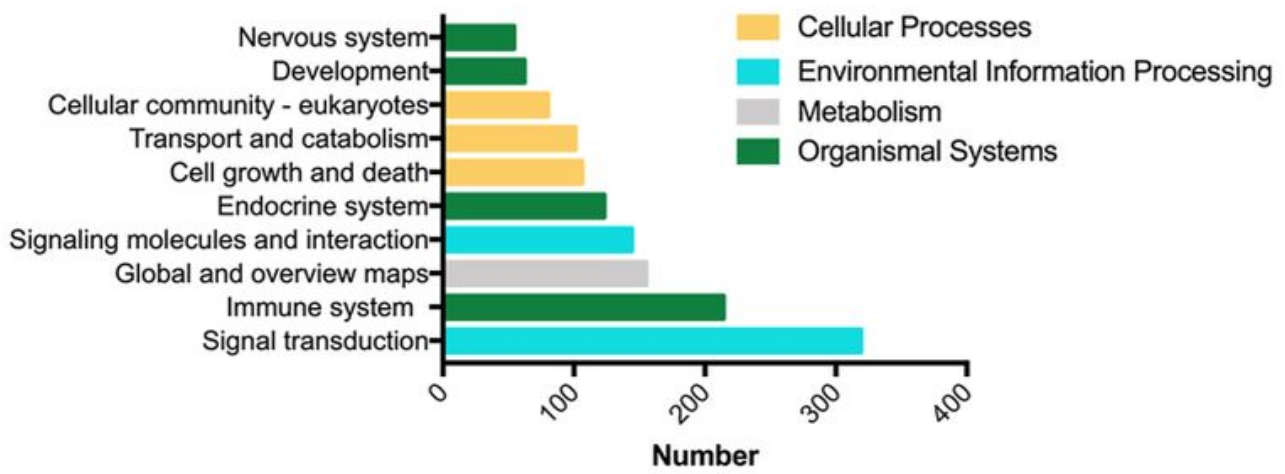

Figure 5

RNA-seq profile of immunocompetent murine pulmonary aspergillosis model 24 hours post inoculation. (a) Diagram of number of unique genes expressed and number of identified genes differentially expressed between groups. (b) Volcano map of DEGs between conidia and hyphae group. (c) KEGG pathway enrichment bubble chart based on DEGs between conidia and hyphae group. The size of the bubble represents the number of genes annotated to KEGG pathway. The color represents the enriched 
significance. Rich Ratio = Term Candidate Gene Number/Term Gene Number. (d) KEGG pathway classification based on DEGs between conidia and hyphae group. The X-axis is the number of genes annotated to a category of KEGG pathway, and the Y-axis is the category of KEGG pathway.

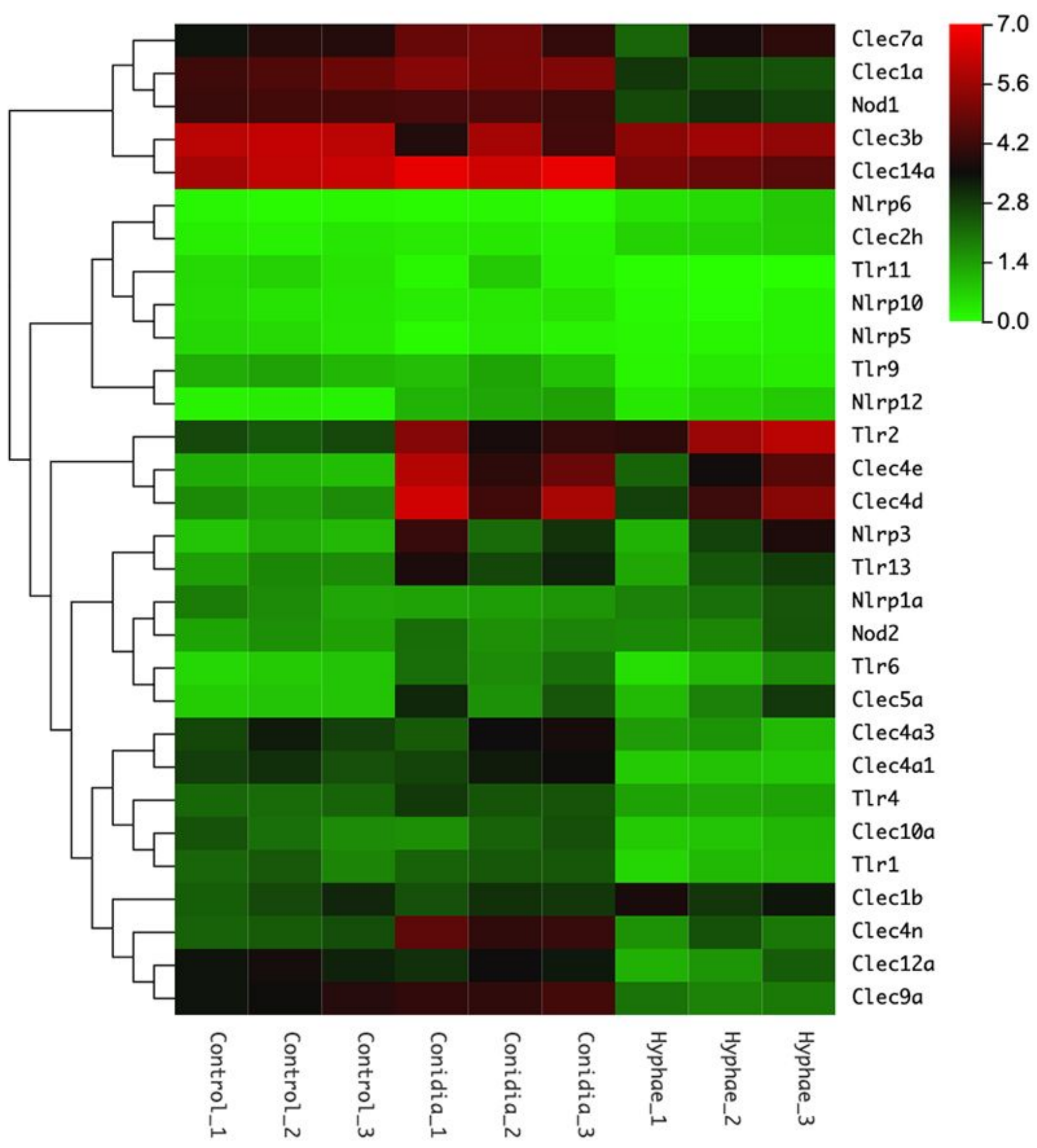

Figure 6

Profile of differentially expressed TLR, Clec and NLR genes. Only genes differently expressed at least between any two groups are displayed. Color indicates the level of log2 $\triangle F P K M+1$. FPKM: Fragments per Kilobase of exon per Million of mapped reads. 
a

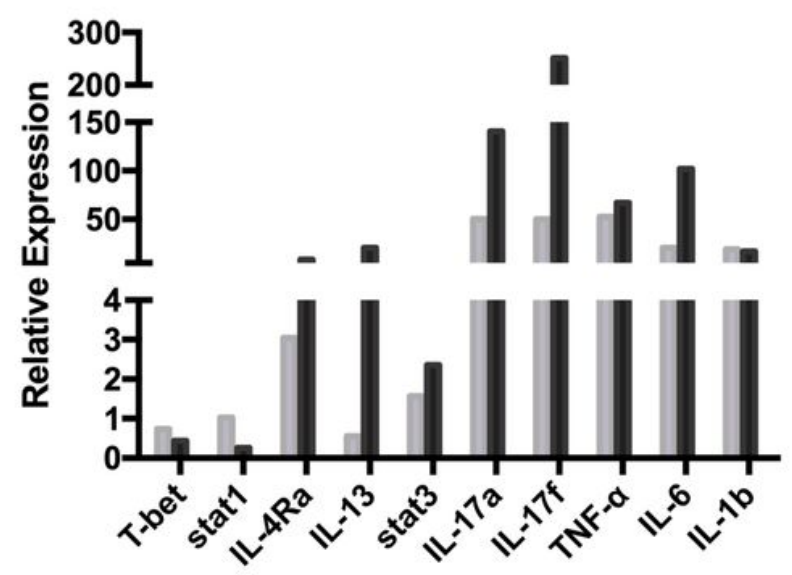

b

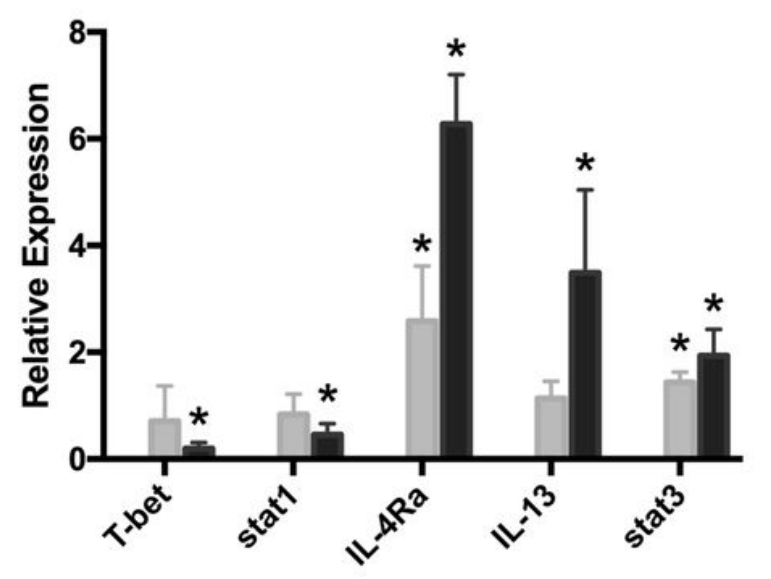

c

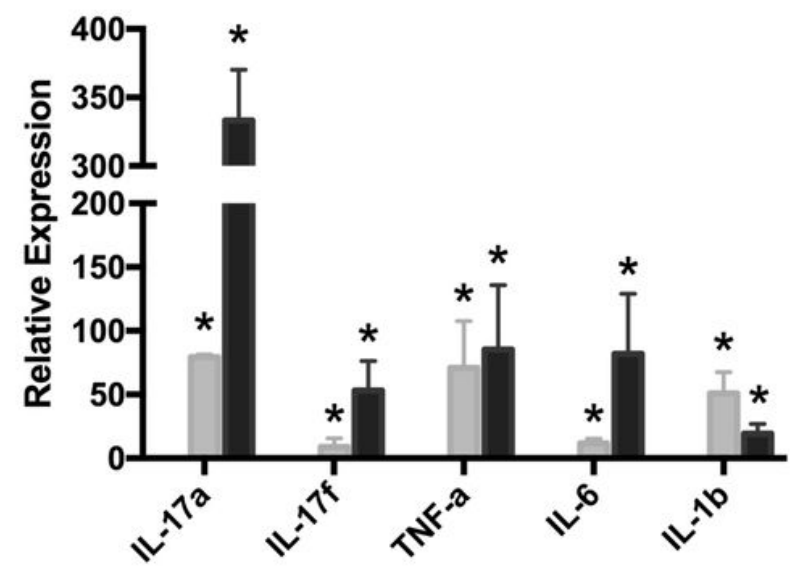

Figure 7

DEGs associated with T cell differentiation and inflammation in murine pulmonary aspergillosis model. Relative expression levels of multiple immunologically relevant genes were determined by RNA-seq (a) and qRT-PCR ( $b$ and $c)$. ${ }^{*} P<0.05$ vs the control group. 